\title{
El encuentro enigmático de Juan Preciado con la pareja de hermanos en Pedro Páramo.
}

\section{Juan Preciado's enigmatic encounter with the sibling couple in Pedro Páramo.}

\author{
Ramón Bárcenas Deanda \\ Departamento de Filosofía / Universidad de Guanajuato (MÉXICO) \\ CE: rbarcenas7@yahoo.com.mx ID ORCID: 0000-0003-3433-9849
}

DOI: $10.32870 /$ sincronia.axxiii.n76.30b19

(CC) $\mathrm{BY} \cdot \mathrm{NC}$

Esta obra está bajo una Licencia Creative Commons Atribución-NoComercial 4.0 Internacional

Recibido: $29 / 03 / 2019$

Revisado: 04/04/2019

Aprobado: $11 / 06 / 2019$

\section{RESUMEN}

Este artículo propone una interpretación de uno de los pasajes más enigmáticos de Pedro Páramo; a saber, el encuentro de Juan Preciado con Donis y su hermana. Preciado se topa con la pareja justo después del despertar de los murmullos del pueblo entero. Rulfo señala en una entrevista que el episodio de los hermanos es sólo una alucinación que el personaje sufre en el momento de su agonía. Esto explicaría situaciones tan extrañas como la desnudez y la soledad de los hermanos, al igual que el suceso en que el cuerpo de la mujer se deshace en lodo. Georg Ronald Freeman relaciona el estado de los hermanos con la condición primigenia de la pareja edénica tras la expulsión del paraíso: soledad, desamparo, desnudez y conciencia de culpa. En este texto se retoman los señalamientos a propósito de la relación del lodo con la culpa. Se plantea que el lodo que la mujer dice ser por dentro no sólo es un símbolo de la condición de pecado en que se encuentra, sino que también nos remite al elemento creador de las potencias vitales. De este modo, el lodo, además de 
representar el pecado, también exhibe el carácter dual, tanto creador como destructor, de la Madre tierra.

Palabras clave: Muerte. Agonía. Lodo. Pecado. Potencias Vitales.

\begin{abstract}
:
This paper proposes an interpretation on one of the most enigmatic events in Pedro Páramo: the meeting of Juan Preciado with Donis and his sister. Preciado meets the couple right after the awakening of Comala's specters. Rulfo says that the couple's story is nothing but a terrible hallucination that the young man suffers during his agony. This would explain the couple's particular state of loneliness and nudity, as well as that mysterious event in which the sister's body melts into mud. George Ronald Freeman relates the couple state with that of the Adam and Eve after being casted out of paradise: loneliness, abandonment, nudity and guilt. This text takes into account the symbolic relation between mud and guilt. It suggests that mud in this story not only represents sin, but it also refers to positive aspects of vital forces. In other words, mud symbolizes guilt as well as Mother earth's creative and destructive attributes.
\end{abstract}

Keywords: Death. Agony. Mud. Sin. Vital Forces.

\title{
I Espectros y murmullos de Comala
}

La historia de Donis y su hermana acontece hacia la mitad de la novela, cuando Juan Preciado está a punto de colapsar ante el asedio de los habitantes de Comala. Antes de la pareja, Juan sufre varios encuentros espectrales que minan su cordura y existencia. El primer contacto es con Abundio el arriero; personaje con quien se topa en el cruce de caminos conocido como Los Encuentros. Esto representa un hecho afortunado para el joven, quien no sabe qué camino tomar para llegar al poblado. Abundio aparece de repente, caminando con sus burros, y le indica que él va precisamente hacia allá. El arriero es una figura que conoce bien las regiones y las veredas remotas, pues su oficio consiste en recorrerlas, transportando mercancías y noticias. Esto lo convierte en un excelente guía 
para quien se encuentra perdido o necesita llegar a un lugar lejano. Por otro lado, las encrucijadas son un lugar propicio para sucesos enigmáticos, tales como apariciones y revelaciones, al igual que posibilitan el paso de una dimensión a otra: “[...] son lugares que provocan al detenimiento y la reflexión, y también lugares de paso de un mundo a otro, de una vida a otra, o de la vida a la muerte" (Chevalier, 1999, p. 446).

Abundio acepta ser su guía y ayuda a Juan Preciado, un ser vivo, a pasar la corriente de polvo que le permite descender al inframundo de Comala. Carlos Fuentes sugiere que el arriero cumple aquí la misma función del barquero Caronte, quien ayuda a Dante a cruzar el río infernal (cf. 2011, p. 127). Hay otros aspectos en que es posible trazar similitudes entre Comala y el Infierno dantesco. Juan subraya el calor asfixiante del lugar y su guía le dice que eso no es nada comparado con el que hace allá. "Ya lo sentirá más fuerte cuando lleguemos a Comala. Aquello está sobre las brasas de la tierra, en la mera boca del Infierno" (Rulfo, 2004, p. 67). Por otro lado, para llegar al pueblo se camina cuesta abajo, como si se fuera al centro de la tierra, lo que evoca los círculos concéntricos del abismo infernal. Preciado rememora las palabras de su madre, a propósito del trayecto: "Sube o baja según se va o se viene. Para el que va, sube; para el que viene, baja"1 (Rulfo, 2004, p. 66). Por último, Comala no es sólo un sitio incandescente, sino, ante todo, un lugar caído de la gracia donde sus habitantes padecen la conciencia del pecado y el arrepentimiento. Es un pueblo doliente habitado por almas condenadas al sufrimiento eterno. En esta región vagan sin esperanza las ánimas de asesinos, suicidas, simoníacos, parricidas, ladrones y traidores. A este pueblo sombrío se le aplica la advertencia escrita en el dintel de la puerta del Infierno dantesco:

Por mí se llega a la ciudad doliente,

por mí se llega al eterno duelo,

por mí se pasa entre los condenados;

[...]

Quienes entráis aquí, dejad toda esperanza. (Alighieri, 2016, p. 96).

\footnotetext{
${ }^{1}$ En cursivas en el texto original.
} 
El siguiente encuentro es con Eduviges Dyada, a cuya posada llega por recomendación del arriero. La mujer lo hospeda en una habitación completamente vacía, aclarando que su madre, Dolores Preciado, recién le avisó de su visita. Le cuenta que las dos fueron muy amigas de jóvenes y se hicieron la promesa de morir juntas para darse valor en el viaje al más allá. La posadera también le confiesa que estuvo a punto de ser su madre, pues sustituyó a Dolores en su noche de bodas. Pero en un momento de la conversación, se queda escuchando un ruido lejano que la lleva a decir en voz baja y como en trance. "— ¿Cuándo descansarás?" La pregunta va dirigida al Colorado, el caballo de Miguel Páramo, que galopa por la región desesperado en busca de su amo. La mujer consulta con Preciado si él también puede oírlo, a lo que éste responde que no; entonces señala que debe ser cosa de su "sexto sentido": un don o una maldición que le permite entablar contacto con seres del más allá. La primera vez que su "don" se revela es la noche en que Miguel Páramo cae del caballo y muere. El espectro del joven se le aparece en su casa y le cuenta lo sucedido. El hijo del cacique iba rumbo a Contla a ver a su novia, y para evitar un gran rodeo obligó al Colorado a saltar un lienzo de piedra. Recuerda haberlo pasado y seguir cabalgando en dirección al poblado, pero por más que avanzó no pudo dar con él. Migue sólo acierta a decir:

Se me perdió el pueblo. Había mucha niebla o humo o no sé qué; pero sí sé que Contla no existe. Fui más allá, según mis cálculos, y no encontré nada. [...] Sé que lo brinqué y después seguí corriendo, pero, como te digo, no había más que humo y humo y humo" (Rulfo, 2004, p. 84).

La presencia de la bruma en este relato es un indicador de la región de los muertos. En el Canto XI de la Odisea, el héroe griego se dirige al Hades en busca del consejo del adivino Tiresias para su retorno a Ítaca. Ulises navega hasta el confín del océano y llega al país de los hombres Cimerios, cuyo reino se encuentran envuelto en sombras y niebla. En ese lugar sombrío se encuentra la entrada al Hades (cf. Homero, 2005, p. 264). La niebla y las sombras son un símbolo de la pérdida de la existencia. Existir es habitar en una realidad determinada por el tiempo y el espacio. Kant los caracteriza como principios organizativos de la percepción (cf. 2006, p. 215). Todo fenómeno 
acontece bajo tales principios, de modo que sin ellos no sería posible tener experiencia del mundo; más aún, sin tiempo ni espacio no habría mundo. Por este motivo al morir una persona, no se rige más por el condicionamiento espacio-temporal. En palabras de Rulfo: "Los muertos no tienen tiempo ni espacio. No se mueven en el tiempo ni en el espacio" (Sommers, 1974, p. 19). La pérdida de tiempo y espacio conlleva la supresión de mundo y la bruma que le oculta el pueblo a Miguel simboliza tal privación.

La tradición cristiana sostiene que el alma se separa del cuerpo al morir. En el trauma de la muerte el alma se desorienta pues sufre la pérdida de mundo. Pero al no hallarse más en esta realidad espacio-temporal, las ánimas pueden aparecer y desaparecer repentinamente. Son en el sentido literal del término "apariciones": manifestaciones visibles de entidades no pertenecientes al ámbito de los vivos. En el Fedón, Sócrates habla sobre el origen de los espectros. Los fantasmas provienen de aquellos hombres que en vida tuvieron un amor desmedido por lo terrenal, al punto que era lo único real para ellos. Al morir, sus almas se aferran a lo mundano y se contaminan de lo tangible, de modo que se tornan visibles (cf. Platón, 2004, p. 74). Además, los cristianos asumen la creencia de que las ánimas en pena vagan por este mundo debido a que fallecen en pecado. En Comala la mayoría de sus habitantes muere sin recibir la absolución, de forma que regresan en busca de gente que rece por ellas. El pueblo vuelve a ser habitado, pero no por seres vivos, sino por una multitud de espectros. En la tragedia Hamlet, el espíritu del rey de Dinamarca se aparece en las noches a los vigías. Este suceso llega a oídos del príncipe, quien decide verlo por sí mismo. El fantasma habla con su hijo y le revela que murió asesinado a manos de su propio hermano, Claudio, mientras dormía su siesta vespertina. El rey lamenta haber sido despojado, no sólo de su vida, su corona y su reina, sino también de la oportunidad de la confesión y la absolución, viéndose condenado a vagar de noche en este mundo.

Soy el espectro de tu padre

condenado a vagar a través de la noche

y a ayunar en el día, rodeado de llamas,

hasta haber purgado los lamentables crímenes 
cometidos en vida, y así extinguirlos (Shakespeare, 2015, p. 177).

Una vez que Eduviges termina de contar la historia de su encuentro con el ánima de Miguel Páramo, le formula a Juan Preciado una de las preguntas más escalofriantes de la novela.

“¿Has oído alguna vez el quejido de un muerto?”-me preguntó a mí.

-No, doña Eduviges.

-Más te vale, hijo. (Rulfo, 2004, p. 85).

Esa misma noche Preciado escucha el grito de Toribio Aldrete. Fulgor Sedano, el administrador de la hacienda, lo asesina por encargo de Pedro Páramo para despojarlo de sus tierras. Tras dejarlo colgado, Fulgor tapia la puerta para que su cuerpo se seque y no encuentre reposo. Juan se encuentra descansando en esa misma habitación y por la noche escucha un fuerte alarido que deja tras de sí un silencio sepulcral. El joven lo describe de la siguiente forma:

No, no era posible calcular la hondura de silencio que produjo aquel grito. Como si la tierra se hubiera vaciado de aire. Ningún sonido; ni el del resuello, ni el del latir del corazón, como si se detuviera el mismo ruido de la conciencia (Rulfo, 2004, p. 93).

Estas palabras revelan el sentido de la advertencia de doña Eduviges. El contacto con seres de ultratumba es un suceso que más nos valdría no vivir; es una experiencia que roba el aliento, paraliza el corazón y aniquila la conciencia. Este suceso revela un cierto grado de quebrantamiento de la vida ante lo espectral.

El quejido de un muerto es un vivencia atroz para el alma humana que lo escucha, pero es inconcebible la acometida de todo un pueblo de sombras y murmullos. Un evento de tal magnitud conduciría no sólo a la pérdida de la conciencia, sino a la muerte misma. Otro encuentro es con Damiana Cisneros, la caporala de la Media Luna, quien cuidó a Juan Preciado de recién nacido. La mujer se presenta en la posada para invitarlo a dormir en su casa. Ambos salen en dirección a la 
Hacienda, y mientras cruzan el pueblo, ella le platica que Comala es un pueblo abandonado, lleno de ruidos de antaño.

-Este pueblo está lleno de ecos. Tal parece que estuvieran encerrados en el hueco de las paredes o debajo de las piedras. Cuando caminas sientes que te van pisando los pasos. Oyes crujidos. Risas. Unas risas ya muy viejas, como cansadas de reír. Y voces ya desgastadas por el uso. Todo eso oyes" (Rulfo, 2004, p.101)

Le cuenta que en un tiempo llegaban hasta la Media Luna sonidos como de fiesta. Fue al pueblo a ver de qué se trataba, pero encontró todo vacío, sin nada ni nadie. Después de un tiempo, dejó de oír el rumor de fiesta, pero esto no le extrañó, pues hasta la alegría cansa. También le narra una historia llena de misterio que le sucedió cuando iba en dirección hacia la posada. Se encontró con un velorio lleno de gente y se detuvo a orar. Una mujer enrebosada se le acercó para pedirle que rezara por ella y se volvió a perder entre las demás. Esa persona era su hermana Sixtina, quien falleció muchos años antes. El encuentro de Damiana con su hermana es ya en sí mismo un suceso enigmático, pero que además la vea en un velorio concurrido, hace de esto un caso prodigioso. Con estas historias, la caporala le advierte de los secretos que encierra ese pueblo sombrío. Pero cuando Juan le pregunta cómo dio con él y si ella sí está viva, la mujer guarda silencio y se desvanece repentinamente, dejándolo solo en las calles vacías. Entonces desesperado la llama a gritos, pero sólo resuena a lo lejos su propio eco:

$$
\begin{aligned}
& \text {-iDamiana! - grité-. ¡Damiana Cisneros! } \\
& \text {-Me contesto el eco: “i ...ana ...neros! i ...ana ...neros!” (Rulfo, 2004, p. 103). }
\end{aligned}
$$

Para su desgracia su llamado sí es atendido, pues despierta a los habitantes de todo el pueblo, y sus gritos desatan tras de sí una algarabía de locura: ladridos, ruidos, voces y canciones. De pronto en una esquina, se oye a dos jovencitas charlar sobre un tal Filoteo Aréchiga, un sujeto encargado de conseguirle mujeres al cacique. Un poco más allá, dos hombres platican sobre la propiedad de la tierra y las cosechas. Por otro rumbo, una pareja de enamorados hablan sobre la posibilidad de 
fugarse. Más allá, sólo murmullos y ecos. Son las ánimas de Comala, reanimadas por la presencia de Preciado, del mismo modo que la sangre vertida en el Hades por Odiseo estimula a los espíritus inertes. Pero además de las voces y los ruidos del pueblo, Juan también ve sombras manifestarse ante él: hombres y carretas vacías pasando por las calles silenciosas del pueblo. Este es uno de los sucesos más perturbadores de la novela: el instante en que un hombre padece los embates de todo un pueblo fantasmal; el momento en que la vida sucumbe ante lo espectral. Juan Preciado está aterrado y piensa en volver por donde llegó, cuando siente que alguien lo toca en los hombros y es invitado a pasar a una casa. Es el hogar de una pareja muy peculiar: Donis y su hermana-amante.

\section{El episodio de la pareja de hermanos.}

Juan entra a una vivienda semi-derruida: "[...] una casa con la mitad del techo caída. Las tejas en el suelo. El techo en el suelo" (Rulfo, 2004, p.106). En ese lugar se hallan un hombre y una mujer completamente desnudos, con sus ropas sobre un equipal. El joven no puede evitar preguntarles si ellos no están muertos, a lo que el hombre responde con brusquedad "está borracho", mientras que la mujer corrige "solamente está asustado". La pareja desnuda son Donis y su hermana. A primera vista, todo parece indicar que no son ánimas en pena como Abundio, Eduviges y Damiana. Juan convive con ellos por más de un día y nota que sus palabras sí suenan, a diferencia de las que había oído antes que sólo se sienten como en los sueños pero sin sonido. Por la mujer se entera que todavía hay gente en el pueblo, pero no osan salir de noche por temor a los aparecidos.

Georg Ronald Freeman subraya las connotaciones bíblicas del estado en que se encuentran los hermanos. Su desnudez y soledad evocan la condición primigenia de la pareja edénica. Su situación también exhibe la inevitable relación incestuosa de los primeros padres, dado el vínculo carnal existente entre ellos. El mandato divino de reproducirse y poblar la tierra los condena al incesto desde el principio. Por otro lado, el estado semi-derruido de la vivienda, con el techo en el suelo, el cielo en la tierra, simboliza el acontecimiento de la caída de la gracia; el destierro del Edén debido a la desobediencia humana a la prohibición divina (cf. Freeman, 1974, pp. 68-71). Representa la pérdida del paraíso, la inocencia, el bienestar y la consecuente conciencia de culpa 
que hace de la existencia un martirio. La manía de buscar culpables por el daño sufrido se resume en el resentimiento que dice: "tú tienes la culpa"; (Adán acusando a Eva); y en la mala conciencia que admite: "yo tengo la culpa", (Eva asumiendo la falta).

El pecado tiene un papel central en la novela. Nadie en Comala está libre de culpa. La serie de faltas cometidas es tan vasta que evoca el Infierno de Dante: lujuriosos, iracundos, orgullosos, asesinos, suicidas, simoníacos, seductores, ladrones, embaucadores, hipócritas, parricidas, traidores. A los pecados cometidos se suma la imposibilidad de la absolución. El padre Rentería no otorga el perdón a Eduviges Dyada debido a que cometió suicidio. Sin embargo, bendice a Miguel Páramo, asesino de su hermano y abusador de su sobrina, y recibe a cambio de su servicio un puñado de monedas de oro. Su falta es la simonía y lo atormenta el remordimiento: "Todo esto que sucede es por mi culpa — se dijo-. El temor de ofender a quienes me sostienen. Porque ésta es la verdad; ellos me dan mi mantenimiento." (Rulfo, 2004, p. 91). Cuando el sacerdote acude a confesarse con el cura de Contla, no obtiene, a su vez, el perdón por permitir la corrupción de su iglesia. La pareja de hermanos, por su parte, no recibe la bendición de un obispo que pasa por Comala. La conciencia de culpa en la mujer es tan fuerte que se niega a salir a las calles por temor a que los demás la vean.

Él no quiere creerlo, pero, ¿verdad que estoy para dar miedo? -y se acercó adonde le daba el sol- ¡Míreme la cara!

Era una cara común y corriente.

-¿Qué es lo que quiere que le mire?

- ¿No me ve el pecado? ¿No me ve esas manchas moradas como de jiote que me llenan de arriba abajo? Y eso es sólo por fuera; por dentro estoy hecha un mar de lodo. (Rulfo, 2004, p. 111).

El lodo es un elemento sucio e inmundo que representa la condición de pecado; pero igualmente es tierra húmeda, propicia para la vida, de modo que también es una referencia a potencias vitales. Su confesión de que por dentro es un mar de lodo parece tener esta doble connotación: sentirse 
impura por la relación incestuosa que mantiene, pero también sentirse plena de impulsos vitales. El relato "Es que somos muy pobres" relaciona las aguas lodosas con el despertar de las pulsiones sexuales. El cuento trata de una familia que padece una serie de desgracias relacionadas con las lluvias torrenciales que han caído en la región. Los aguaceros provocan el desbordamiento del río, el cual arrasa con todo a su paso: plantíos, árboles, animales y casas. En condiciones normales, el río es fuente de vida de la misma forma que las apetencias sexuales son propicias para la reproducción. Pero cuando el agua alcanza niveles desmesurados, conlleva destrucción y muerte. Los impulsos vitales, al igual que el río, también se desbordan y arrasan con reglas morales.

El temor de la familia es que la hija adolescente, la Tacha, se vaya de piruja, como sus hermanas mayores, ahora que la crecida de las aguas se ha llevado su vaca la Serpentina. Los padres esperaban que la muchacha se entretuviera con ella, hasta que se presentara una propuesta de matrimonio. La Serpentina representaba la posibilidad de una vida decente para la joven. La única esperanza que les queda es que el becerro haya sobrevivido. La Tacha llora desconsoladamente por la pérdida de su animal y su hermano ofrece una descripción muy sugerente de este suceso.

Por su cara corren chorretes de agua sucia, como si el río se hubiera metido dentro de ella. [...] De su boca sale un ruido semejante al que se arrastra por las orillas del río, que la hace temblar y sacudirse todita, y, mientras, la creciente sigue subiendo (Rulfo, 2000, p. 59).

La relación del llanto con las aguas lodosas del río es una alusión al despertar de las pulsiones sexuales en la Tacha, como si estos impulsos incontenibles se desbordaran por sus ojos, manchando al salir su vestido rosa. El narrador nota, además, sus senos incipientes y puntiagudos que se agitan en los espasmos de su llanto, "[...] como si de repente comenzaran a hincharse para empezar a trabajar por su perdición" (Rulfo, 2000, p. 59). El mar de lodo que la mujer dice ser por dentro remite a estas mismas pulsiones: a la necesidad vital de unión y reproducción humanas. Esto es lo que ella le explica al obispo: "Yo le quise decir que la vida nos había juntado, acorralándonos y puesto uno junto al otro. Estábamos tan solos aquí, que los únicos éramos nosotros. Y del algún modo había que poblar el pueblo" (Rulfo, 2004, pp. 111-112). 
Un suceso terrible tiene lugar cuando la pareja sale de la vivienda, dejando solo a Juan Preciado. Ya casi al anochecer, una mujer flaca entra a la casa, toma un bulto de sábanas y se va de puntitas por donde llegó. Juan piensa que es otro espectro y se paraliza de terror. Lo único que puede hacer, para evitar la presencia, es voltear su rostro hacia el cielo gris, en dirección a la estrella junto a la luna. En la cosmogonía náhuatl, Xólotl es la representación de la estrella vespertina, mientras que Quetzalcóatl lo es del lucero matutino. Xólotl es su hermano gemelo, su sombra, su nahual, y se relaciona con la noche y el inframundo. Esta deidad tiene la función de acompañar y proteger al Sol en su travesía por el Mictlán, del mismo modo que el perro (xoloitzcuintli) conduce a los recién fallecidos al país de los muertos (cf. Spranz, 2006, pp. 419-420). La notable vinculación de Xólotl con el submundo es lo que explica la creencia de que la luz de la estrella vespertina permite a los muertos salir y confundirse con los vivos. No se olvide que Rulfo contempló en un principio titular su novela: Una estrella junto a la luna (cf. Jiménez de Baez, 1994, pp. 149-150).

La visión provoca en Preciado una experiencia límite: ve pasar ante sus ojos los sucesos vividos en sentido inverso, desde el instante presente hasta el momento en que se despide del arriero. La perturbación del curso temporal, ya sea porque retroceda o se ralentice, es un notable indicio de una situación anómala. Juan está conmocionado y pierde la conciencia; cuando vuelve en sí, se halla en la cama de otate junto a la hermana de Donis. Preciado se incorpora y ella le ofrece algo de cenar. Le explica que la persona que tanto lo asustó es su hermana y de ella obtuvo la comida. La mujer le pide que regrese a la cama y él accede acostarse con ella. Entonces tiene lugar el suceso más extraño del episodio de los hermanos incestuosos. Juan despierta a medianoche debido al calor y al sudor. La joven sigue durmiendo y de su boca sale un ruido como de estertor. En ese momento percibe que el cuerpo que tiene a su lado se está deshaciendo en lodo.

El calor me hizo despertar al filo de la medianoche. Y el sudor. El cuerpo de aquella mujer hecho de tierra, envuelto en costras de tierra, se desbarataba como si estuviera derritiéndose en un charco de lodo. Yo me sentía nadar entre el sudor que chorreaba de ella y me faltó el aire que se necesita para respirar (Rulfo, 2004, pp. 116-117). 
El suceso del cuerpo deshaciéndose en lodo es de un misterio muy particular. La mujer ha dicho que por dentro es un mar de lodo, en alusión al pecado en que se halla. La doble connotación del lodo como símbolo de inmundicia y de fertilidad hace referencia a las cualidades creadora y destructora de la madre Tierra. En la cosmogonía náhuatl la Tierra es representada por tres diosas que exhiben tales atributos. Coatlicue, "la de la falda de serpientes", es la madre creadora de los dioses: del Sol, la Luna y las estrellas. Es la deidad más antigua y venerable, referida como "nuestra madre" o "nuestra abuela" (cf. Caso, 2003, pp. 72-73). Cihuacóatl, "la mujer serpiente", es la patrona de las mujeres que mueren durante el parto, llamadas Cihuateteo, las cuales gritan y aúllan en el aire por la noche. Alfonso Caso sugiere que esta deidad deviene posteriormente en la figura popular de "la Llorona". Además, en el mito de la creación del hombre, Cihuacóatl recibe los huesos preciosos del Mictlán, los muele y los mezcla con barro, al tiempo que Quetzalcóatl vierte su sangre en la mezcla para dotar de vida nuevamente al hombre (cf. León-Portilla, 2006, p. 184). La tercera deidad es Tlazoltéotl, "diosa de la inmundicia", quien es la patrona de los partos y los nacimientos, lo cual revela su carácter creador. Pero también es una deidad destructora pues es la devoradora de inmundicias. Tlazoltéotl se alimenta de la inmundicia en un sentido amplio del término, ya que consume tanto los restos corpóreos como también los pecados (cf. Caso, 2003, pp. 73 y 75). El pecado, consistente en la embriaguez y en el desenfreno sexual, es inmundo como el lodo porque conlleva la impureza moral. Caso subraya que el pecador es incluso representado en los códices como "el comedor de inmundicias". El episodio de la mujer fundiéndose en lodo es una alusión a estas cualidades de fertilidad e inmundicia, y al carácter creador y destructor de la tierra.

Por otro lado, Rulfo señala una línea de interpretación muy sugerente. Subraya que la historia de los hermanos-amantes es una alucinación de Juan Preciado, estimulada por el terror que se ha apoderado de él. Todo el episodio es un delirio que sufre en el instante previo a su muerte. En una entrevista que le concede a José Carlos González Boixo², en abril de 1983, a propósito de la

\footnotetext{
${ }^{2}$ Entrevista publicada como Apéndice III en: Rulfo, Juan (2004) Pedro Páramo, Madrid, Ediciones Cátedra, pp. 247251.
} 
primera edición de Pedro Páramo en Ediciones Cátedra, se le pregunta por la pareja enigmática y el autor responde lo siguiente:

-Todo indica que los personajes con los que se encuentra Juan Preciado están muertos; sin embargo, hay una pareja de hermanos que parecen estar vivos.

-Ah, no, pero es una alucinación. No existen, es una alucinación que tiene (Juan Preciado) dentro del terror mismo. Por ejemplo, se le convierte en un montón de barro, de lodo, la mujer esa. Todo eso es absurdo, ¿no? Son alucinaciones que él tiene, de que encontró a esta pareja y que esta pareja lo quiso dar alojamiento. Son alucinaciones que preceden a la muerte (Rulfo, 2004, p. 248).

Si asumimos que el encuentro con la pareja incestuosa es el resultado de una alucinación de Juan Preciado, estaríamos, de cualquier forma, ante su experiencia de agonía. La agonía, del griego agón, significa lucha; es un duelo entre la vida y la muerte; es también un estado de crisis y de tensión que puede dar lugar a delirios portentosos. Rulfo aborda el tema de la agonía relacionada con la angustia y la alucinación en, cuando menos, tres ocasiones: en el episodio de la pareja de hermanos aquí referido, en un guion para cortometraje titulado El despojo y en el manuscrito "IBA ADOLORIDO. AMODORRADO DE CANSANCIO", publicado en Los cuadernos de Juan Rulfo. Estos escritos tratan de la distorsión del sentido del tiempo y de la angustia que se experimentan en el instante previo a la muerte. También permiten situar a Rulfo en la tradición de cuentos fantásticos como "Un suceso en el puente del río Owl" de Ambrose Bierce y "El milagro secreto" de Borges, los cuales tratan de la bifurcación del tiempo imaginario y del tiempo real que acontece en la experiencia delirante de la agonía.

El cortometraje El despojo (1960), dirigido por Antonio Reynoso, se filmó los fines de semana y sin un guion preexistente. Jorge Ayala Blanco explica que Rulfo fue creando diálogos y eventos a partir de una "muy difusa línea argumental" durante el rodaje mismo. También señala que la obra es "[...] el primer experimento de ficción aleatoria que realizó el cine mexicano independiente"(Rulfo, 1980, p. 105). El guion se publica en 1980 junto con otros textos para cine del 
escritor jalisciense. La trama del corto es como sigue. Pedro, un campesino, se enfrenta a don Celerino, cacique del pueblo, quien busca quedarse con su esposa Petra. El campesino está dispuesto a cederle sus tierras y su casa, pero nunca su mujer. Para protegerla decide irse del lugar con su familia; aunque también está determinado a enfrentarse al cacique si se lo topa. Al caminar por las calles del pueblo, es encarado por don Celerino; se hacen de palabras y terminan por balearse el uno al otro. Pedro, malherido, está a punto de caer pero la imagen se congela y acto seguido lo vemos correr a su casa por su mujer y su hijo enfermo, Lencho. La familia huye de la región y en el trayecto pasan por múltiples situaciones angustiantes, como el asedio del Nahual, la muerte de Lencho y la visión idílica de Petra semidesnuda, cepillándose el cabello. Pero la complejidad de todo lo vivido es sólo un delirio que Pedro padece en el instante fugaz en que cae moribundo sobre el guitarrón que lleva en sus espaldas (cf, Reynoso, 1960).

Por último, el escrito "IBA ADOLORIDO. AMODORRADO DE CANSANCIO" forma parte de los textos encontrados en los cuadernos de trabajo de Juan Rulfo. Yvette Jiménez de Báez lo incorpora en la quinta sección titulada MANUSCRITOS DE RELATOS. (cf. Rulfo, 1994, pp. 103-108). Dicho escrito también aborda el tema de la agonía alucinante La historia versa sobre un joven, Hermenegildo, quien camina ofuscado por campos de girasoles. De su mano cuelga una 38 super colt, que disparó hace poco contra un hombre. Hermenegildo se lo topó al mediodía en el pueblo en compañía de sus hijos. La víctima se alegra de verlo e intenta saludarlo, pero recibe una lluvia de plomo que lo mata en el acto. Mientras el asesino escapa por el campo, le viene a la memoria el motivo que lo orilló a tal acción. A la edad de trece años su hermana Carmela fue víctima de una violación. El joven averigua que el responsable es un tal Aniceto; sale a buscarlo para ajustar cuentas, pero recibe una golpiza. La humillación lo orilla a irse del pueblo con la idea fija de vengarse algún día. Años después regresa armado y cumple su fatal promesa. El homicida continúa huyendo hasta que cae la noche. Se detiene y decide volver por su hermana y sus sobrinos; ahora él se hará cargo de ellos. Retorna por los mismos campos y entra al pueblo por sus calles desiertas. Llega al lugar del asesinato y para su sorpresa aún está ahí tendido el cuerpo de Aniceto. De repente vuelve la luz del medio día; oye gritos desesperados y ve gente corriendo hacia él. También él yace 
en el suelo herido de muerte, y de golpe una densa oscuridad le nubla la vista. El joven se disparó a sí mismo después de acribillar a su cuñado. La historia de su fuga por el campo aconteció sólo en su interioridad, en el instante previo a su muerte. Estos relatos muestran que en el doloroso trance de la agonía el sentido del tiempo se dilata, lo cual posibilita que los personajes vivan, en su imaginación, sucesos complejos en un instante del tiempo real. Episodios misteriosos, tales como, la fuga de un asesino por el campo, la huida de una familia de campesinos o el encuentro de Juan Preciado con la pareja de los hermanos-amantes.

\section{Referencias}

Alighieri, D. (2016) Divina comedia, Madrid: Ediciones Cátedra.

Caso, A. (2003) El pueblo del Sol, México: Fondo de Cultura Económica.

Chevalier, J. (1999) Diccionario de los símbolos, sexta edición, Barcelona, Editorial Herder.

Freeman, G. R. (1974) La caída de la gracia: clave arquetípica de Pedro Páramo. En Sommers, J. (Ed.) La narrativa de Juan Rulfo. Interpretaciones críticas. México: SEP/ Setentas.

Fuentes, C. (2011) La gran novela latinoamericana, México: Alfaguara.

Homero, (2005) Odisea, Madrid: Editorial Gredos.

Jiménez de Báez, Y. (1994) Juan Rulfo, del páramo a la esperanza. Una lectura crítica de su obra (2a Ed.)

México: Fondo de Cultura Económica y El Colegio de México.

Kant, I. (2006) Crítica de la razón pura, Buenos Aires, Editorial Losada.

León-Portilla, M. (2006) La filosofía náhuatl estudiada en sus fuentes, México: Universidad Autónoma de México.

Platón (2004) Diálogos III, Fedón, Fedro y Banquete, Madrid: Editorial Gredos.

Reynoso, A. (Dir.) (1960): El despojo, México: Cine foto.

Rulfo, J. (1980) El gallo de oro y otros textos para cine, México: Ediciones ERA.

Rulfo, J. (2000) El Llano en llamas, Madrid: Ediciones Cátedra.

Rulfo, J. (1994) Los cuadernos de Juan Rulfo, México: Ediciones ERA.

Rulfo, J. (2004) Pedro Páramo, Madrid: Ediciones Cátedra.

Shakespeare, W. (2015) Hamlet, Edición bilingüe, Madrid: Ediciones Cátedra. 
Sommers, J. (1974) Los muertos no tienen tiempo ni espacio (un diálogo con Juan Rulfo). En Sommers, J. (Ed.) La narrativa de Juan Rulfo. Interpretaciones críticas, México, SEP/ Setentas.

Spranz, B. (2006) Los dioses en los códices mexicanos del grupo Borgia. Una investigación iconográfica, México: Fondo de Cultura Económica. 